\title{
QUEEN'S
UNIVERSITY
BELFAST
}

\section{Gosport must be the tipping point for professional hierarchies in healthcare - an essay by Philip Darbyshire and David Thompson}

Darbyshire, P., \& Thompson, D. R. (2018). Gosport must be the tipping point for professional hierarchies in healthcare - an essay by Philip Darbyshire and David Thompson. BMJ, 363, [k4270].

\section{Published in:}

BMJ

\section{Document Version:}

Peer reviewed version

Queen's University Belfast - Research Portal:

Link to publication record in Queen's University Belfast Research Portal

Publisher rights

This work is made available online in accordance with the publisher's policies. Please refer to any applicable terms of use of the publisher

\section{General rights}

Copyright for the publications made accessible via the Queen's University Belfast Research Portal is retained by the author(s) and / or other copyright owners and it is a condition of accessing these publications that users recognise and abide by the legal requirements associated with these rights.

Take down policy

The Research Portal is Queen's institutional repository that provides access to Queen's research output. Every effort has been made to ensure that content in the Research Portal does not infringe any person's rights, or applicable UK laws. If you discover content in the Research Portal that you believe breaches copyright or violates any law, please contact openaccess@qub.ac.uk. 


\section{Ending the 'Doctor - Nurse Game' for all health professionals:}

\section{Gosport as a tipping point}

\section{The horror of Gosport}

The Gosport Independent Panel Report ('the Panel') into the deaths of around 600 patients at Gosport War Memorial Hospital (GWMH) [1] is a massive wake-up call to every health professional. The families involved deserve more than for this report to be shelved and forgotten.

Many of us imagined we would never read anything more appalling than the Francis or Morecambe Bay Reports. We were wrong. The Gosport report [1] concluded that 'older patients', some of whom had been admitted for 'rehabilitation' or 'respite' (2.96:26), had their lives "shortened", largely by the administration of "continuous opioid use" (2.96:26) that was "not clinically indicated or justified." [1], v111)

Although prescribed by a doctor, the drug cocktails (e.g. diamorphine, midazolam and hyoscine) were usually administered by nurses who often determined exact dosages and any 'PRN' additional doses to be given. Gosport's litany of communications failure, prevarication, deliberate delay, cover-up, obfuscation, professional self-interest and buckpassing will shock even the jaded who have read all of this before. Here, we focus specifically on dysfunctional interprofessional communication and the notorious "DoctorNurse Game" [2] . 


\section{The 'Doctor - Nurse Game' charade}

Reading Gosport, we wonder if doctors and nurses have made any progress in improving working relationships since Stein's initial 'Doctor-Nurse Game' description [2] some 50 years ago. Stein described a dance of deference, a "transactional neurosis" (p.702), whereby medical, nursing and societal hierarchies shaped how nurses can influence care, treatment and clinical decisions only by subtle suggestion and "without appearing to" by ensuring that ideas and proposals never appear as their direct suggestions, but only ever as the doctor's autonomous decision (p.701). Such subterfuge was essential to 'the game' lest they incur rebukes and humiliation for daring to "insult and belittle" (p.700) a doctor. In the game, nurses learn to use such wiles while doctors maintain their "overdetermined preservation of omnipotence" (p.700). The results of this game are "disastrous" (p.702) and as occurred at Gosport, patients suffer. We would like to believe that this institutionalised "self-censoring" [3] (p.945) was all in the past and that interprofessional communications have moved on, but we have read too many studies and heard too many colleagues recount bitter experiences of vitriolic condemnation to believe this.

Thus at Gosport [1], nurses at multiple levels were systematically dissuaded and were en masse unable or unwilling to challenge or question the prescribing practices of a doctor $(3.25, p .48)$

\section{The lethal silence}

These tyrannies of silence and norms of niceness are no 'game'. They are harming and killing patients. People are dying unnecessarily because some health professionals 'don't 
want to make a fuss' or worry they might 'upset' the 'very caring' doctor [1], 1.7:4) while others want to enjoy their lofty status of being beyond questioning.

This insidious "status hierarchy" [3] (p.943) blights both nursing and medicine in all settings, both primary and secondary, but especially in our hospitals. The 'game' seems to affect doctor-nurse relationships far more than Allied Health staff or others. As Stein himself noted in connection with multidisciplinary teams broadening, "The sociologist, for example, is not willing to play that kind of game" [2] (p.216). Its continuation cannot be dismissed as the fault of a few 'bad apples' when rotten orchards are the real issue. Such hierarchies and game-based relationships are not outlier aberrations. This "fear of reprisal" [3] (p.944) is 'the norm' [4], p.576) for many. A student nurse or new graduate RN can be just as wary of questioning a 'Modern Matron' as a resident would be intimidated by challenging a consultant. As one nurse remarked, "questions can only go down (...) you are very careful about questions going up the chain of command." [5]. Other studies have shown that many health professionals will ignore dangerous practice rather than intervene or question another professional.

An airline pilot, whose 37 year old wife died following what was to be relatively 'minor' nasal surgery, wrote of nurses 'dancing around' her post-op care needs, knowing full well that she was in danger but unable to state this explicitly and clearly to her doctors:

"The nurses were clearly aware that things were going wrong, but seemed unable to say anything (...) It's often 'simply not your place' to speak up.. [6], p.2444) 
These perverse charades and their calamitous consequences are what pass for 'communication' among too many health professionals.

Comparisons between health care and the airline industry are often made, but pilots and aircrew have much more 'skin in the game' than health professionals. If aviation has serious flaws impeding safety, planes may crash and crew members as well as passengers will die. There is no such Sword of Damocles hanging over the heads of most of those implicated in the last 50 years of scandal reports. Many of those with the greatest culpability for poor care or 'hospital scandals' face no loss of status, livelihood, freedom or life. They merely move on to their next health service, charity or quango position [7].

Prior to the airline industry's worst ever disaster when two jumbo jets collided at Tenerife airport, the airline industry played its own 'Pilot-Air Crew Game', where 'the captain is God, and what he says goes' was accepted wisdom and the basis of cabin relationships, a socalled 'authority gradient' [8]. The same hierarchical gradient metastasized the DoctorNurse Game. The Tenerife disaster claimed 583 lives and fundamentally changed an entire industry. GWMH "shortened the lives" [1] of around 600 people, yet many worry that this will just be another momentary blip on the 'business as usual' radar of health professional relationships.

This lethal subservience and toxic deference whereby those deemed more 'junior' show great reluctance to question or challenge those with more power and status is endemic within health systems $[7,9]$. Health professionals rightly fear retribution, disapproval, career-limiting consequences and worse if they dare to question or challenge colleagues in any discipline. Surely, enough is enough. For over 50 years patients and families have 
endured preventable errors, wrong-site operations and unnecessary and avoidable deaths because some health professionals and systems are dysfunctionally dangerous, yet also seemingly 'untouchable'. This is our issue as health professionals. No Minister or CEO can fix this for us.

\section{Not 'choice' but professional imperative}

We need a better approach to interpersonal relationships than the 'choice of courage' in the face of the pretences of the Doctor-Nurse Game. Every health professional from new student to Modern Matron and Consultant must understand that their practices and decisions will be discussed, questioned and challenged, as essential elements of health professional identity and practice. The days of unilateral decision-making and unfettered 'clinical freedom' are over. The days of 'Don't you know who I am?' are over. Being a registered health professional means that you will be questioned and challenged just as we expect to do the same as an act of professional courtesy and service to colleagues. Nembhard and Edmondson [3] have shown that "leader inclusiveness helps crossdisciplinary teams overcome the inhibiting effects of status differences, allowing members to collaborate in process improvement" (p.941) and that "traditional status differences in health care may be overcome, facilitating full participation in cross-disciplinary team improvement efforts" (p.958). The Doctor-Nurse Game can be ended.

Good collegial relationships, hallmarked by an overwhelming focus on patient safety and wellbeing over professional niceties, historical status and comedies of manners should be a legacy of reports like Gosport if we are to genuinely claim that 'lessons have been learned'. There should be no place in modern healthcare for the bully, prima donna, 
micromanager, egomaniac, narcissist or others There should be no 'job for life' for those such as one study's feared senior staff who would; 'lash out', 'have a meltdown', 'explode', 'blast off', and 'unravel', ensuring that colleagues remained silent, as speaking up was considered so 'provocative' as to be "detrimental to safety"[10], p.332]. If any health professional feels unable to work in a collegial, respectful and open manner, then it is time for them to find another career. Their power, status and freedom to do whatever they like, however they choose and their imperious indignation at being 'questioned' is being paid for by patients' lives and their loved ones' grief. It is far, far too high a price to pay.

Changing health professional hierarchies and relationships that are often complex and resistant is not easy. Stein observed that "the forces militating against change are powerful" [2] (p.214), There is no single 'magic bullet' that will prevent the next GWMH scandal. As doctors and nurses, however, we can and must do something to minimise or prevent the lethal 'Doctor-Nurse Game' from being played for yet another 50 debilitating years.

\section{Could these suggestions help?}

- Call out all instances of rude, overbearing, bullying behaviour from any health, hospital or university figures, be they a Dean, Chief Nurse, Consultant or CEO. Overbearing thuggery bolsters a culture where fearful silence and 'looking the other way' become the norm [9]. There may be lessons in the success of today's social movements such as \#metoo and \#timesup suggesting that bottom-up resistance and change challenging the powerful is possible.

- Create educational and clinical opportunities, where doctors, nurses, other health professionals and managers can learn and work effectively together, not as masters 
and handmaidens, but as equal colleagues in the wider project of enhancing safety, protecting patients, working as partners with relatives and families and promoting their wellbeing. Such initiatives can and do make a positive difference [3][11].

- Involve patients and families early and at every opportunity [12]. Perhaps they will be less inclined to witness and then avert their gaze in the face of appalling professional behaviour.

- Work with existing research and evidence about creating psychologically and professionally 'safe', 'open' questioning, healthcare organisations [3]. We do not need 'more research', we need more leaders with the courage and creativity to bring alive what we already know.

- Put our money where our principles are. If Athena Swan incentives have worked for women's participation in science, perhaps we could create funding incentives that reward radical initiatives stimulating demonstrable improvements in health professional relationships.

Gosport must become a watershed in health care, where health professionals finally say 'enough', 'no more'. No other patients should be harmed because health professionals stayed silent, were silenced $[1](1.22$, p.6) or encountered institutional deafness where their warnings were never listened to. That is what we owe to the dead of Gosport and their relatives. Nothing less.

\section{Key messages}

The horrors so forensically detailed in the report into the deaths of around 600 patients at Gosport War Memorial Hospital (GWMH) confront doctor-nurse communications and relationships like few others. 
We can no longer continue to play or tolerate the notorious 'Doctor-Nurse Game' with its attendant deceits, pretences and dangers.

Patient safety, experience and modern interprofessional relations demand a more open, collegial, respectful and non-hierarchical mode of communicating and relating between doctors, nurses and indeed all health professionals.

\section{END}

\section{References}

1 Gosport Independent Panel. Gosport War Memorial Hospital The Report of the Gosport Independent Panel. London: Department of Health 2018. https://www.gosportpanel.independent.gov.uk/media/documents/070618 CCS207 CCS031832207 61 Gosport Inquiry Whole Document.pdf

2 Stein LI. The doctor-nurse game. Arch Gen Psychiatry 1967;16:699-703. doi:10.1001/archpsyc.1967.01730240055009

3 Nembhard IM, Edmondson AC. Making it safe: The effects of leader inclusiveness and professional status on psychological safety and improvement efforts in health care teams. J Organ Behav 2006;27:941-66.doi:10.1002/job.4134

4 Bould MD, Sutherland S, Sydor DT, et al. Residents' reluctance to challenge negative hierarchy in the operating room: a qualitative study. Can J Anesth 2015;62:576-86. doi:10.1007/s12630-015-0364-5

5 Thomas EJ, Sherwood GD, Mulhollem JL, et al. Working together in the neonatal intensive care unit: provider perspectives. J Perinatol 2004;24:552-9. doi:10.1038/sj.jp.7211136

6 Bromiley M. Have you ever made a mistake? R Coll Anaesth Bull 2008;48:24425.https://www.rcoa.ac.uk/system/files/CSQ-Bulletin48.pdf\#page=17

$7 \quad$ Hammond P, Bousfield A. Shoot the Messenger How NHS whistleblowers are silenced and sacked. Private Eye 2011;1292 :15-22.http://drphilhammond.com/blog/wpcontent/uploads/2011/11/Shoot the Mesenger FINAL.pdf

8 St Pierre $M$, Scholler A, Strembski D, et al. Do residents and nurses communicate safety relevant concerns?: simulation study on the influence of the authority gradient. Anaesthetist 2012;61:85766.http://europepmc.org/abstract/med/23011044

9 Francis R. Freedom to speak up: An independent review into creating an open and honest reporting culture in the NHS. 2015. http://freedomtospeakup.org.uk/wpcontent/uploads/2014/07/F2SU Executive-summary.pdf 
10 Szymczak JE. Infections and Interaction Rituals in the Organisation: Clinician Accounts of Speaking Up or Remaining Silent in the Face of Threats to Patient Safety. In: Allen D, Braithwaite J, Sandall J, et al., eds. The Sociology of Healthcare Safety and Quality. Chichester, UK: John Wiley \& Sons, Ltd 2016. 140-54. doi:10.1002/9781119276371.ch9

11 Reeves S, Pelone $F$, Harrison R, et al. Interprofessional collaboration to improve professional practice and healthcare outcomes. Cochrane Database Syst Rev 2017;6:CD000072. doi:10.1002/14651858.CD000072.pub3

12 Foot C, Gilburt H, Dunn P, et al. People in control of their own health and care. London: The King's Fund 2014.

https://www.patientvoicesouth.swcsu.nhs.uk/media/medialibrary/2015/01/People in control of $t$ heir own health and care The Kings Fund.pdf

Licence for Publication

The Corresponding Author has the right to grant on behalf of all authors and does grant on behalf of all authors, an exclusive licence (or non exclusive for government employees) on a worldwide basis to the BMJ Publishing Group Ltd to permit this article (if accepted) to be published in BMJ and any other BMJPGL products and sublicences such use and exploit all subsidiary rights, as set out in our licence (http://group.bmj.com/products/journals/instructions-for-authors/licence-forms).

Competing Interest

Please see our policy and the unified Competing Interests form http://resources.bmj.com/bmj/authors/editorial-policies/competing-interests. Please state any competing interests if they exist, or make a no competing interests declaration. 